\title{
A Study on the Translation Strategy of Theme Structure in English News Headlines in the Omnimedia Era
}

\author{
Weina Ouyang and Dan Li* \\ Foreign Language Education Institute, Beihua University of Jilin 132000, China \\ 694839505@qq.com, Bettylidan@qq.com \\ * The corresponding author
}

Keywords: Omnimedia; News headlines; Thematic structures; Translation strategies

\begin{abstract}
In the context of the omnimedia era, English news is one of the quickest ways to communicate information between China and foreign countries. English news headlines have their own characteristics. To some extent, news headlines can reveal the inherent nature of the news. The thematic structure of the English news title is the focus of the discourse, the entry point, which is the object of rheme structure. Because the subjective position always occupied by Thematic structure, the special grammatical function of the sentence head position, it determines the special function of the individual subject, the subject of the complex and the subject of the sentence in the whole news headline. In the translation of the thematic structure, the appropriate use of translation strategies can highlight the functionality of the news and highlight the important function of the title.
\end{abstract}

\section{Introduction}

The study of the language features of English news will help to master the development trend of the world and improve the level of translation research and practice of various media news industries. Through the study of the translation of the thematic structure of the English news headlines, readers will not only learn to read the news headlines, but also appreciate the content of the full text through the news headlines, correctly understand the vocabulary of the English news headlines, grammar and rhetoric and other characteristics, determine the title of the moral meanings with the better eyes of news to see the world.

\section{Research on News Headlines and Thematic Structure}

English News Headlines. Domestic research on news headlines began in 1980s when scholars made the preliminary results on the English title. Zhu Wenjun held that the title of English is an integral part of news English. But in words, sentences and many other aspects, English title is in a unique style. Yu Yang studied from the perspective of corpus on the network of English news headlines that there are some differences in the English news title between the lexical grammar and the traditional grammar.

The study of news headlines started earlier and more thorough research in the foreign countries, such as George Mauton, who thinks that the title has the function of selling articles, generalizing content, beautifying the layout while Christie believes that the title must be concise and clearly interesting.

Research on the Thematic Structure of News. Omestic scholar Deng Qiong believes that the editor will generally lead the first in the title of the object in the news reports so that readers generally understand the news and journalists tend to report. Zhang Miao makes the point of view from the perspective of English news that to the large extent the thematic structure reveals the inner nature of English news headlines.

The research for the thematic structure abroad is systemic and in-depth. Matthews, the founder of the Prague school of linguists, proposed the concept of the theme in 1939 for the first time, whose 
sentence theory of foreground theory (also known as "practical categorization theory") divided the sentence into the theme, transition and rheme. Halliday, a British linguist, based on the theory of Matthews, proposed a semantic segmentation of the discourse, which is defined from the function rather than the distribution. In his introduction to Functional Grammar, he further divided the theme into simple themes, multiple themes and clause themes.

\section{Research on Thematic Structural Translation of English News Headlines}

According to Halliday's theory, the thematic structure of English news title is the focus of discourse, the entry point, which is the concern or perspective object of rheme struture. Because the subjective position always occupied by Thematic structure, the special grammatical function of the sentence head position, it determines the special function of the individual subject, the subject of the complex and the subject of the sentence in the whole news headline. English news headlines can be divided into individual theme titles, multiple theme titles and clause theme titles from the perspective of the thematic structure.

Translation of Individual Theme Titles. If the theme title is an independent part, which can not be divided into smaller functional units, then it is known as the individual title. The main form of the theme includes a noun phrase, adverb phrases or prepositional phrases.

(1) North Korea $\|$ Warned (The New York Times)

North Korea is warned. (The New York Times)

(2) Bank in Pledgeuty $\|$ to Protect Pensions (The Times)

Bank mortgage protection pension (The Times)

According to the theory of the semantic division of the thematic structure and the theory of the lexical division, the front part of the symbol \| constitutes the main component of the news headline, and the translator shows the importance of the subject prompt and the whole sentence effect.

Translation of Multiple Theme Title. The multiple theme title refers to the composition of the English news headline contains the main theme of the composition, including the language composition and interpersonal composition. According to Halliday's theory, the empirical component is called the thematic theme. News headline contains more than the main theme of the composition of the main theme, mainly the title of the news itself, characteristics of the decision. Discourse composition and interpersonal composition, because of a certain degree of modification, in the news headline, would not be taken as the main component while the opposite empirical component can not be omitted, which is the core of the main theme.

(1) Bad Outcome, Maybe, but Metsited Are Feeling Good (The New York Times)

The results may be unsatisfactory, but Metsited feel good (The New York Times)

(2) Oh, boy $\|$... the teenage party of a life-time (The Times)

Hi! There is a unique party for teenagers in their whole lives (The Times)

These two sentences basically outline the basic characteristics of the news multiple theme title and the biggest feature--the inclusion of more ingredients. In the second example, simply relying on Boy will not cause the reader's attention, and through the continuous component $\mathrm{Oh}$ is different, which shows the theme tips by continuous theme structure to a common term into the object of concern.

Translation of Clause Theme Title. The clause theme title is composed of a clause, which refers to the clause in the traditional clause or the nonphabet form of the verb. Due to the concise, novel and striking features of the news headlines including the subject limitation by length and subject matter with the characteristics of the prominent subject (action performer), the title of the sentence is small in the whole news headline. However, these clauses on the sentence play the thematic role of the theme in order to emphasize some of the ingredients reflecting the author's writing style or in the article needs, etc..

(1) Your music shaped my life, $\|$ Bashir told Jackson (The New York Times) 
Your music casts out my life, and Bashir told Jackson (The New York Times)

(2) If Bush beats the blather, $\|$ his placemen win (The Times)

If Bush is still making nonsense, his rivals will win (The Times)

In the above examples, the sentence acts as the subject of the news headline. These sentences as a whole semantic unit, play a certain emphasis on the role of translation should also be corresponding to emphasize the important role of the main theme.

\section{Translation Strategies of the Thematic Title Structure of the English News Headlines}

The Wording of Thematic Translation. In the newspapers and magazines, the layout space is very valuable. Editors should try to keep the smallest amount of information in the smallest amount, which puts forward a high demand on the English news headlines. So the English title used nouns and short words midget words widely. The main words of the title should not only have powerful meaning with large amount of information, but also have wide range of grammatical compatibility, the study of the wording is necessary.

English news headlines are omitted in order to achieve the purpose of saving the layout, which is often used in the news headline omitted usage. But with rules, the arbitrary omitted should grasp a big principle that is to delete the words,

For example, the title, Equal Stress uses the omitted usage, whose complete statement should be "Is this equal stress?"

ISDN (Integrated Services Digital Network)

PC (personal computer)

TMD(Theater Missile Defense)

memo (memorandum)

AIDS (Acquired Immune Deficiency Syndrome)

mod (modern)

lab (Labor)

lib (Liberal)

nukes (nuclear explosives)

heliport (helicopter airport)

NATO (North Atlantic Treaty Organization)

SALT (Strategic Arms Limitation Talks)

The Vocabulary and the Translation of Slang in the Main Theme. The vocabularies of the English news headlines also use the Vogue Words. Since the vitality of the news comes from the new era, the title and content of the report must be closely linked to all new things, new phenomena, new ideas and new trends with the high rate of occurrence come out. In the English title, especially in the local news headlines, editors often use slang as the main vocabulary to create a cordial, humorous atmosphere. How to translate the fashionable words and slang in the English title and make it reach the standard of translation needs our study on the translation strategy through examples.

(1) Economy Grows Slowly As Unemployment, Inflation Rise-Economists.

Economists Say That The Economy Grows Slowly As The Unemployment And Inflation Rise.

(2) Malaria Still Menaces Quarter Of Humanity-French Professor.

A French Professor Says That Malaria Still Menaces A Quarter Of The Humanity.

Tense and Voice Translation Affected the Theme Structure. The tense in the English title is generally not used in the past, which is now known as Journalistic Present tense. For instance, the English news headlines use the active voice frequency is much higher than the passive. From the rhetorical point of view, the expression of active voice is more colorful, more appealing and more direct. At the time of translation, due to the different linguistic features and manifestations of Chinese, there are different requirements for the translation of tenses and voices. 
(1) Belgium Supports Francs, Denies It Will Quit "Snake”.

Belgium Supports the Francs and Denies It Will Quit the "Snake".

(2) Guangzhou Fair Closes, Trade Booms.

The Guangzhou Fair Closes and the Trade Booms.

(3) Yeltsin: Muslim Nations Call For End To Tension In Bosnia and Herzegovina.

Yeltsin Says That Muslim Nations Call For An End To The Tension In Bosnia Herzegovina.

(4) Shanghai: Resplendent Pearl New China.

(Shanghai Is A Resplendent Pearl New China.)

\section{Conclusion}

Because of the diversity and complexity of the subject-predicate structure of English news headlines, it is divided into individual theme title, multiple theme title and title (Clause theme title), the relevance of the content of the English news title itself --- English wording, vocabulary and rhetorical content complex, tense and voice expression form and other factors, in the title of the main theme of the translation strategy to take what The difficulty of the study. The main structure of the news headlines should take into account the above factors from the reality, combined with a variety of translation strategies to make the English news headlines in the main structure more prominent role.

\section{Acknowledgements}

Social Science Project of Jilin Province Department of Education "13th Five - Year", A Study on the Translation Strategy of Theme Structure in English News Headlines under the Omnimedia Era. Project No: JJKH20170070SK.

\section{References}

[1] Crystal D: Investigating English Style, Vol. 3 (2009) No. 2, p45

[2] Mott G F: New Survey of Journalism (Barnes and Noble, Inc, UK, 1957)

[3] Halliday M A K. An Introduction to Functional Grammar (Foreign Language Teaching and Research Press, China, 1994)

[4] Bloor T: The Functional Analysis of English: a holliday an Approach (Foreign Language Teaching Press, China, 2001)

[5] Duan Muyiwan: Features Analysis in Titles of English News. [J]. 2011, 4(01).

[6] Meara P. Modeling vocabulary loss [J]. 2004, 25(02)

[7] Hu Xuanwei: Comprehensive Analysis of English News (Shanghai Foreign Language Press, China) 